\title{
The Contribution of Prosody to the Foreign Accent of Chinese Talkers' English Speech
}

\author{
Liu, Xing 1$) \cdot$ Lee, Joo-Kyeong2)
}

\begin{abstract}
This study attempts to investigate the contribution of prosody to the foreign accent in Chinese speakers' English production by examining the synthesized speech of crossing native and non-native talkers' prosody and segments. For the stimuli of the foreign accent ratings, we transplanted gender-matched native speakers' prosody onto non-native talkers' segments and vice versa, utilizing the TD-PSOLA algorithm. Eight English native listeners participated in judging foreign accent and comprehensibility of the transplanted stimuli. Results showed that the synthesized stimuli were perceived as stronger foreign accent regardless of speakers' proficiency when English speakers' prosody was crossed with Chinese speakers' segments. This suggests that segments contribute more than prosody to native listeners' evaluation of foreign accent. When transplanted with English speakers' segments, Chinese speakers' prosody showed a difference in duration rather than pitch between high and low proficiency such that stronger foreign accent was detected when low proficient Chinese speakers' duration was crossed with English speakers' segments. This indicated that prosody, more specifically duration, plays a role though the prosodic role is not overall as significant as segments. According to the post acoustic analysis, the temporal features contributing to making the duration parameter prominent as opposed to pitch were found out to be speaking rate, pause duration and pause frequency. Finally, foreign accent and comprehensibility showed no significant correlation such that native listeners had no difficulty listening to highly foreign accented speech.
\end{abstract}

Keywords: prosody, segment, foreign accent, comprehensibility, TD-PSOLA, transplanted stimuli

\section{Introduction}

This study investigates the relative contribution of prosody over segments to the evaluation of foreign accent and finds out the specific parameters of prosody contributing to the accentedness of L2 speech. As speech mainly consists of two distinct components such as segments and prosody, foreign accented speech has drawn attention to the questions of which factor between segments and prosody has a more dominant effect on native listeners' detection of foreign accent and how

1) University of Seoul, fayemeteor@naver.com

2) University of Seoul, jookyeong@uos.ac.kr, Corresponding author

This work was supported by the 2011 research fund of the University of Seoul. An earlier version of this study was presented at the fall conference of the Speech Science Society of Korea in 2011.

Received: July 28, 2012

Revised: September 20, 2012

Accepted: September 20, 2012 they play a role in native listeners' perception. This curiosity has produced many studies in the foreign accent of non-native talkers' speech (e.g., Wode, 1980; Flege, 1987b; Mack, 1989; Kuhl, 1991; Flege, 1991; Morley, 1991; Avery \& Ehrlich, 1992; Flege, 1993; Flege et al., 1995; Munro, 1995; Flege et al., 1997a; Pallier et al., 1997; Wayland, 1997; Walley \& Flege, 1998; Magen, 1998; Missaglia, 1999; Riney, Takada \& Ota, 2000; Pennington \& Ellis, 2000; Piske et al., 2001; Tsukada et al., 2004; Tsukada, 2005; Altenberg, 2005; Kang, 2010). Foreign accent has been defined as non-native talkers' incorrect articulation and pronunciation (Greene and Wells, 1927) and deviation from native speakers' criterion (Bent, et al., 2008). The previous studies on the articulatory deviance of the foreign accented speech have primarily focused on segmental features (Brennan et al. 1975; Flege \& Hillenbrand, 1984; Flege, 1987; Mack, 1989; Flege, 1993; Mildner \& Horga, 1999; Riney, Takada and Ota, 2000; Levi et al., 2007). They investigated which segmental features affect non-native speech to be accented, showing how the degree of foreign accent is correlated with the VOT duration of stop consonants, the 
formant frequencies of vowels, segment deletion, insertion and substitution. Comparatively fewer studies have investigated the contribution of prosody to foreign accented speech or the relative weight of segments and prosody.

It seems to be important to separate prosodic information from segments in order to examine the prosodic role alone in speech, but the technology of low pass filtering was first utilized to cut off higher frequencies entailing segmental information to see how prosody contributes to accented speech (Munro, 1995; Jilka, 2000; Trofimovich \& Baker, 2007; Van Els \& Debot, 1987). Due to the fact that the low pass filtered speech, which sounds mostly like humming, contains only pitch contour, it is not considered as natural speech. Therefore, the naturalness of the synthesized L2 speech may be the issue such that native listeners may not have enough information to judge foreign accentedness.

Recent studies on the independent role of prosody in L2 speech have developed a transplanting technology which crosses L1 segments with L2 prosody and vice versa (Boula de Mareuil, Brahimi \& Gehdrot, 2004; Boula de Mareuil, Marotta \& Adda-Decker, 2004; Boula de Mareuiil \& Vieru-Dimulescu, 2006). The transplanted speech, though still synthesized, contains both segmental and prosodic information, bringing up no naturalness problem. The previous studies attempted to find out which factor between prosody and segments plays a more important role in the perception of foreign accent, even though the relative weight of segment and prosody has not been conclusive yet. Furthermore, very few studies examined individual prosodic parameters of accented L2 speech to see which is the most influential to foreign accentedness among duration, pitch and amplitude. Along this line, this study adopts the recent technology of transplanting and attempts to cross English native talkers' segments with non-native Chinese talkers' duration and pitch and vice versa. This enables us to figure out which of duration and pitch is a more significant attribute to making L2 speech more accented.

The low pass filtering technology has been utilized in some previous studies. Van Els \& Debot (1987) made use of the low pass filtered synthesized speech and examined the contribution of pitch in the assessment of foreign accent. Both L1 and L2 recordings of five sentence stimuli were manipulated in two different types: (1) the speech containing segmental information alone without pitch and (2) the low-pass filtered speech with intonation only. The non-pitch phenomenon made the speech monotone and reduced the identification of native or foreign accented speech by listeners. They conclusively contended that intonation played a major role in the evaluation of foreign accent.

In Munro (1995)'s study, both low-pass filtered and unfiltered speech stimuli were provided for foreign accent ratings. L2 Mandarin Chinese and L1 Canadian speakers described a cartoon picture in the target language of English. Then 20 untrained English native listeners rated foreign accent for both their filtered and unfiltered sentences. The results indicated that listeners were able to distinguish native and non-native speech when they were presented with non-segmental speech. This suggested there is sufficient information in the intonation component to detect foreign accent.

Flege et al. (1995) carried out an experiment that used a low-pass filtering technology to manipulate speech recordings of L2 Italian and L1 English speakers. Both L1 and L2 speech was manipulated to preserve only amplitude and pitch. The English native listeners rated foreign accent for both their original and manipulated speech samples. Native speakers obtained better foreign accent ratings than non-native speakers. This indicated that the speech containing amplitude and pitch with no segmental information could have sufficient information to differentiate native from non-native accented speech.

Trofimovich and Baker (2007) investigated the extent to which the suprasegmental features contributed to foreign accentedness in the low-pass filtered with no segmental information. They measured both the prosody-based (stress timing, peak alignment) and fluency-based parameters (speech rate, pause frequency, and pause duration) in L2 speech. All the features affected the perception of foreign accent of non-native speech except for the peak alignment, which suggested that L2 prosody alone might make an independent contribution to accentedness.

Although the low-pass filtering technology successfully separated segments from prosody and showed how prosody played a role in foreign accented speech, the isolated pitch and time information might not serve as natural speech. It might mislead naïve listeners to judging the foreign accent of L2 speech in different criteria because the humming-like sound is not common speech they use (Lee \& Liu, 2012). Therefore, Boula de Mareuil and Vieru-Dimulescu (2006) recently adopted the TD-PSOLA (time domain pitch synchronous overlap and add) algorithm in their study. It is the most advanced technology which enables one speaker's temporal and tonal components of prosody to be switched with the other speaker's 
segments. In their own study, they took advantage of the fact that Spanish and Italian are phonologically/phonetically very similar. They asked Spanish and Italian native speakers to produce almost the identical Spanish and Italian sentences and transplanted Spanish speakers' pitch and duration onto Italian speakers' segments, and vice versa. Spanish and Italian listeners evaluated the original and transplanted speech samples, identifying whether the speech was native Spanish, Italian accented Spanish, Spanish accented Italian, or native Italian. Both Italian and Spanish listeners perceived the synthesized speech of Italian segments and Spanish prosody as Spanish and the speech of Spanish segments and Italian prosody as Italian. This indicated prosody was a more influential factor than segments and played an important role in recognizing foreign accented speech. However, their results may be in some sense attributed to the fact that segmental patterns and structure in Spanish and Italian are mostly indistinguishable except for some variations (Lee \& Liu, 2012). The role of segments might be comparatively insignificant in detecting foreign accent from Spanish accented Italian and Italian accented Spanish. If L1 and L2 are quite distinctive phonologically and phonetically, the independent roles of segments and prosody would be more clearly observed when they are crossed with each other. Therefore, the current study attempts to investigate the contribution of prosody in Chinese accented English speech, assuming that L1 English and L2 Chinese talkers' English are considered distinctive. We take Boula de Mareuil and Vieru-Dimulescu (2006)'s work as a source of reference to conduct stimuli synthesis in which L1 English and L2 Chinese talkers' English segments and prosody are transplanted with each other.

Foreign accent is frequently discussed along with comprehensibility (Coleman, 1962; Varonis \& Gass, 1982; Gass \& Varonis, 1984; Flege, 1988; Anderson-Hsieh \& Koehler, 1988; Nguyen, 1993; Munro \& Derwing, 1995; Derwing and Munro, 1997; Matsuura, Chiba \& Fujieda, 1999; Schmid \& Yeni-Komshian, 1999; Munro \& Derwing, 2001; Major, Fitzmaurice, Bunta \& Balasubramanian, 2002; Derwing, Munro \& Thomson, 2008; Kang, 2010). As demonstrated in Derwing and Munro (1997), comprehensibility refers to listeners' evaluation of difficulty in understanding the non-native speech. It is completely an independent paradigm from foreign accentedness (Munro and Derwing, 1995; Derwing and Munro, 1997). Anderson-Hsieh \& Koehler (1988) firstly paid attention to the effect of foreign accent on native listeners' comprehension. They brought up a question about whether native speech would be easier to understand than non-native speech, and asked 224 English listeners to rate the foreign accent for 3 Chinese speakers' and 1 native speaker's reading of an English passage in different speaking rates. They found out that native speakers' speech was easier to comprehend and that strong accented L2 speech decreases native listeners' comprehensibility, especially in fast rate. However, it may be their limitation to have a small number of subjects; therefore, it appears to be premature to generalize their results.

Munro and Derwing (1995) also examined the relationship between foreign accent and comprehensibility. They presented 10 Mandarin L2 speakers' and 2 English L1 speakers' descriptions of a cartoon to 18 English native listeners. The listeners rated foreign accent and comprehensibility and showed that native speech was always perceived as less accented and easier to understand than non-native speech. Their results are consistent with those of Derwing and Munro (1997). L2 talkers who were rated as stronger foreign accent were also rated as lower comprehensibility. On the other hand, Munro \& Derwing (1999) made a contrastive claim such that it is not always true that the speech rated as stronger accent is rated as relatively more difficult to understand. There has not been a solid and consistent argument about how foreign accent of L2 is associated with native listeners' comprehensibility. Moreover, the previous work has all investigated natural L2 speech. The current study, therefore, attempts to observe synthesized speech in which prosody and segments are transplanted with each other between L1 and L2 and observe the correlation between foreign accent and comprehensibility.

\section{Experiment}

\subsection{Accentedness Task}

We recruited twelve (six males and six females) Mandarin Chinese speakers of English to select high and low proficiency talkers. They were all exchange students at a university in Seoul and had the same length of English learning experience (8 years) in China. However, the experimenters intentionally composed three low and three high proficiency Chinese speakers of English for each female and male group based on their impressionistic standards of fluency. Prior to recording the stimuli, they participated in the Accentedness Task for their proficiency level. They were asked to read an English passage (see Appendix 1), and their recordings were presented to three 
English native speakers for foreign accent ratings at a 9-point Liker scale $(1=$ very strong foreign accent and $9=$ no foreign accent). The Chinese speakers who were rated with the scores above 7 were sorted as high proficiency and those below 3 were classified as low proficiency. Eight Chinese talkers of English, in total, participated in recording the stimuli for the transplanting synthesis, and they were also balanced in gender, with two males and two females in each proficiency level.

In order to transplant non-native speech with native speech, English native speakers (two males and two females) also participated in our experiment as talkers. They were native English teachers who work at a university in Seoul. None of them were reported to be able to speak other foreign languages.

\subsection{Procedure}

Eight Chinese talkers and four English native talkers were asked to read five English sentences including an average of 5-8 syllables. We chose short sentences to avoid the emergence of temporal errors when transplanting. Long sentences are more likely to create unnatural outputs due to the differences in speech rate between native and non-native speech. More specifically, the segments of non-native talkers may have more chance to be temporally too compressed, and the segments of native talkers are more likely to elongate, resulting in unnatural synthesized speech. The five sentence stimuli were varied in sentence type: statement, yes-no question, wh- question, and exclamatory sentences. We utilized the Praat program for recording and transplanting. The talkers were asked to read the sentences as naturally in a normal speech rate. The recording was carried out at the sampling rate of $44.1 \mathrm{kHz}$.

60 sentences were produced ( 12 talkers $* 5$ sentences) in total. Prior to the transplanting synthesis, we segmentized all the talkers' recordings; the segmentations should be the same in the number and order of segments between two utterances for the sake of transplanting. If deletion or insertion of a phone emerged, we added a pause of $0.01 \mathrm{~ms}$ at the position where there was a missing segment to match the number of segments in the corresponding sentence. The added pause of $0.01 \mathrm{~ms}$ was not audible and merely functioned as mapping with the segment missed. We made use of the TD-PSOLA (time domain pitch synchronous overlap and add) algorithm to generate transplanted stimuli, and its program script was available in Yoon (2006). If there is the substitution at the (sub) phonemic level in the non-native talker's sentence, we labeled the correct phonemic signal. The prosodic parameters of pitch $(\mathrm{F})$ and duration (D) were examined because pitch and duration have been generally considered as salient prosodic cues in English while intensity makes relatively little attribute (Tekman, 1997). This has been also accepted in Boula de Mareuil \& Vieru-Dimulescu (2006)'s study; they transplanted pitch and duration only with segments in their prosody-segment warping technique. Figure 1 indicates the principle of the prosody transplantation process (Lee \& Liu, 2012). L1 talkers' prosody including pitch (F) and duration (D) were copied onto the strings of segments in L2 talkers' speech, and vice versa. Prosody crossings split into two parameters and generate three different synthesized outputs in each of the components, segment $1 \&$ prosody 2 and segment $2 \&$ prosody 1. The prosodic parameters of pitch and duration were transplanted individually and in combination of two; therefore, the synthesized sentences such as segment $1+$ prosody 2 pitch $(F)$, segment $1+$ prosody 2 duration $(D)$, segment $1+$ prosody 1 duration \& pitch $(D F)$ are created in the component of segment $1 \&$ prosody 2 and segment $2+\operatorname{prosody} 1$ pitch $(F)$, segment $2+$ prosody 1 duration (D), segment $2+$ prosody 2 duration \& pitch $(D F)$ are generated in the component of segment 2 \& prosody 1.

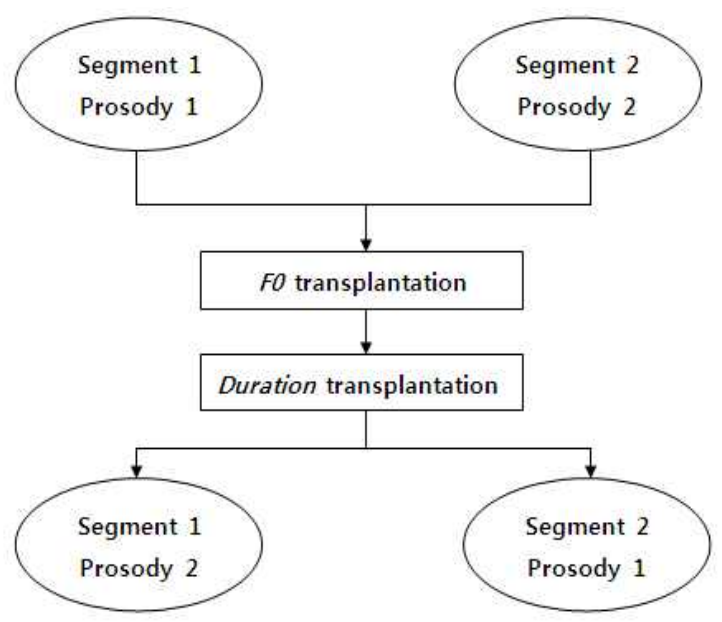

Figure 1. Diagram of the prosody transplantation process.

In addition to transplanting inter-language talkers' speech, we crossed prosody and segments within the same level of proficiency and the same gender to make both segment and prosody information from either L1 or L2 alone. This is mainly to ensure that all the stimuli should be synthesized for the sake of consistency. All the stimuli were transplanted by four ways: gender-matched native talkers' (NTs') prosody with non-native talkers' (NNTs') segment, gender-matched NNTs' prosody with NTs' segment, gender-matched NT's prosody with NT's 
segment, and gender-matched NNT's prosody with NNT's segment. 330 transplanted stimuli were in total obtained for the perception experiment: 240 synthesized outputs (8 non-native talkers $* 5$ sentences $* 3$ prosodic parameters $* 2$ times) from the inter-language crossings. 30 synthesized sentences within native talkers $(2$ native talkers $* 5$ sentences $* 3$ prosodic parameters), and 60 within non-native talkers (4 non-native talkers $* 5$ sentences $* 3$ prosodic parameters).

Another group of eight English native speakers served as listeners to rate foreign accent and comprehensibility. All the synthesized stimuli were randomly presented to the listeners in the SuperLab program. They were instructed to press the keyboard to give scores of the foreign accent and comprehensibility after they listened to the stimuli. Both foreign accent and comprehensibility ratings were conducted at a 9-point scale $(1=$ very strong foreign accent/very difficult to understand, $9=$ no accent/very easy to understand) (Trofimovich and Baker, 2007). Native listeners' ratings of the foreign accent and comprehensibility were submitted to t-test, ANOVA and Pearson correlation for statistical analysis.

\subsection{Results and discussion}

\subsubsection{Foreign accent}

The foreign accent scores of the transplanted stimuli of English talkers' prosody with Chinese high proficiency talkers' segments and those of English talkers' segments with Chinese high proficiency talkers' prosody are shown in Figure 2. For the three prosodic parameters, the foreign accent scores are significantly higher for Chinese talkers' prosody with English talkers' segments than for English talkers' prosody with Chinese talkers' segments (D: $t=29.547, \mathrm{p}<0.05$; $\mathrm{DF}$ : $\mathrm{t}=23.743, \mathrm{p}<0.05$; $\mathrm{F}=30.407, \mathrm{p}<0.05)$.

The results of low proficiency talkers in Figure 3 are similar to those of high proficiency talkers in Figure 2. For all the prosodic parameters, the foreign accent scores are significantly greater for the stimuli of Chinese talkers' prosody with English talkers' segments than those of English talkers' prosody with Chinese talkers' segments ( $D: t=28.629, p<0.05$; DF: $t=29.202$, $\mathrm{t}<0.05 ; \mathrm{F}: \mathrm{t}=23.911, \mathrm{p}<0.05)$

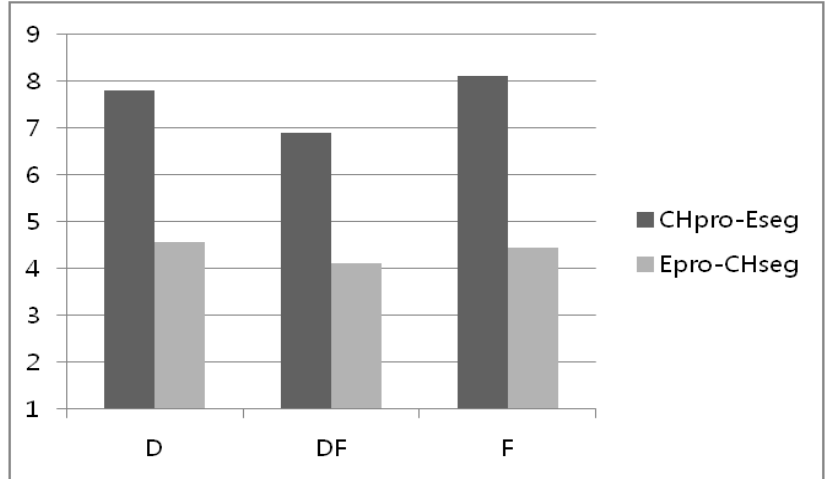

Figure 2. Foreign accent scores of the transplanted sentences of Chinese high proficiency talkers' prosody with English talkers' segments, and English talkers' prosody with Chinese high proficiency talkers' segments $\left(\mathrm{E}_{\mathrm{pro}}=\right.$ English talkers' prosody, $\mathrm{E}_{\mathrm{seg}}=$ English talkers' segments, $\mathrm{CH}_{\mathrm{seg}}=$ Chinese high proficiency talkers' segments, $\mathrm{CH}_{\text {pro }}=$ Chinese high proficiency talkers' prosody)

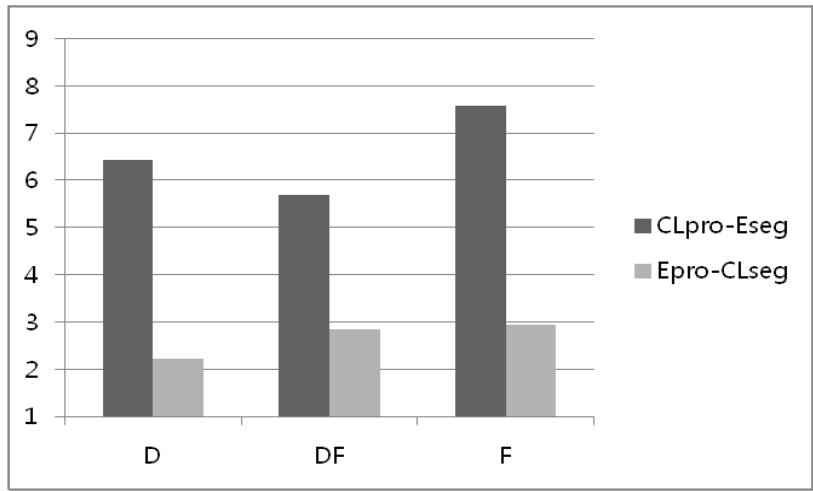

Figure 3. Foreign accent scores of the transplanted sentences of Chinese low proficiency talkers' prosody with English talkers' segments, and English talkers' prosody with Chinese low proficiency talkers' segments $\left(\mathrm{CL}_{\mathrm{seg}}=\right.$ Chinese low proficiency talkers' segments, $\mathrm{CL}_{\mathrm{pro}}=$ Chinese low proficiency talkers' prosody).

The results in Figure 2 and Figure 3 indicate that English listeners detected a stronger foreign accent for the synthesized speech of English talkers' prosody with Chinese talkers' segments regardless of the proficiency or prosodic parameters. This suggests that segment information of non-native talkers plays a more important role than prosody in the perception of foreign accent. Listeners appear to rely on segments more than prosody when perceiving sentences; it may be due to the fact that segments play a primary role in delivering semantic information of the speech.

A comparison of foreign accent scores between Chinese high and low proficiency talkers are shown in Figure 4. Chinese high proficiency talkers acquired significantly better accent scores 
than low proficiency talkers when their segments are different and native prosody was identically crossed (D: $\mathrm{t}=8.686, \mathrm{p}<0.05$, DF: $\mathrm{t}=6.186, \mathrm{p}<0.05, \mathrm{~F}: \mathrm{t}=11.066, \mathrm{p}<0.05$ ). High proficiency talkers' outperformed articulation of L2 segments may be consistent with Imai, Walley and Flege (2004)'s claim that good L2 perception links to good pronunciation.

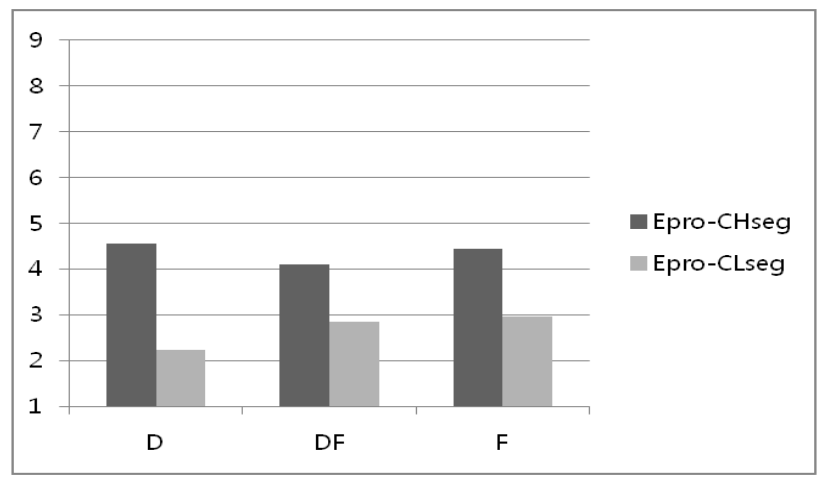

Figure 4. Foreign accent scores of the transplanted sentences of English talkers' prosody with Chinese high and low proficiency talkers' segments.

When both of Chinese high and low proficiency talkers' prosody were transplanted with English talkers' segments, the difference was shown only when native talkers' duration and pitch were crossed with Chinese talkers' prosody ( $D$ : $\mathrm{t}=7.493$, $\mathrm{p}<0.05, \mathrm{DF}=9.804, \mathrm{p}<0.05, \mathrm{~F}: \mathrm{t}=3.602, \mathrm{p}=0.724)$ as illustrated in Figure 5. When the segmental information is identical, Chinese high proficiency talkers show better performance in duration, and this might be due to the fact that their speech rate is more similar to that of native talkers. In other words, when the same native segments were transplanted onto L2 high proficiency fast speech and L2 low proficiency slow speech, native listeners mostly relied on the speech rate in rating the foreign accent. On the other hand, the pitch parameter does not seem to play a prominent role. When the pitch contour was overlaid onto the native segments, high proficiency talkers' pitch did not induce a weaker foreign accent than that of low proficiency talkers. Therefore, this can be interpreted as saying that Chinese L2 talkers' production of English intonation does not show a significant difference between high and low proficiency.

Figure 6 presents the foreign accent scores for the stimuli crossing between the same L1 talkers and between the same L2 talkers. It is not surprising that the synthesized stimuli between English talkers were rated the highest and that those between Chinese high proficiency talkers were rated higher than low proficiency talkers. The differences were statistically significant (D: $F=13.334, p<0.05 ; \quad D F: F=12.982, p<0.05, \quad F: F=16.475$, $\mathrm{p}<0.05)$

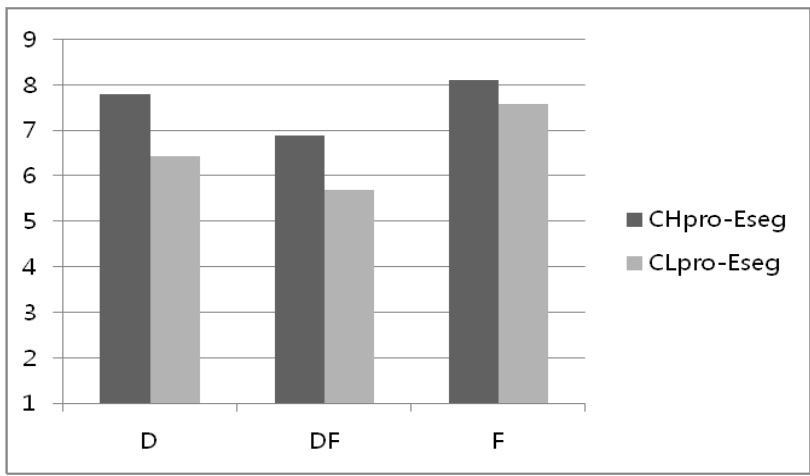

Figure 5. Foreign accent scores of the transplanted sentences of English talkers' segments with Chinese high and low proficiency talkers' prosody.

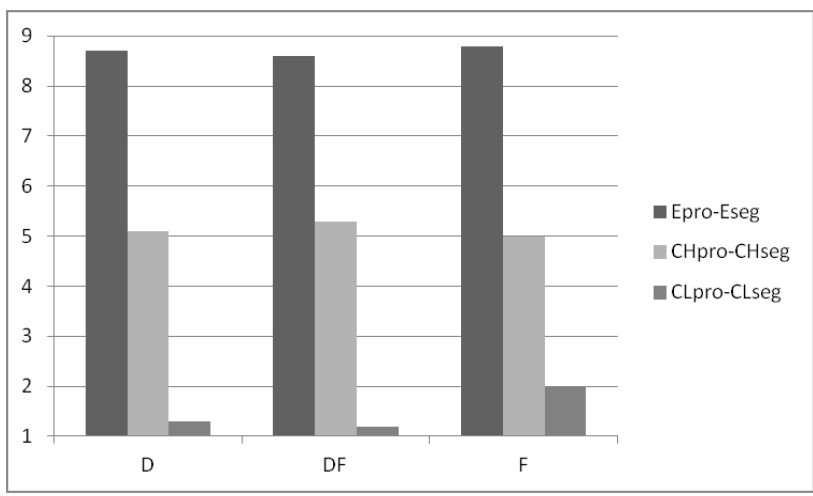

Figure 6. Foreign accent scores of the transplanted sentences of English talkers' prosody-segment, Chinese high proficiency talkers' prosody-segment, and Chinese low proficiency talkers' prosody-segment.

Figure 7 shows a comparison of the foreign accent scores for inter-language talkers' crossings and intra-language talkers' crossings. The prosody-segment crossing stimuli within native talkers were the least accented, the stimuli of English segments and Chinese prosody were rated as less accented than those of English prosody and Chinese segments, and the synthesized stimuli within non-native Chinese talkers were the most accented. When you compare the leftmost two bars in each prosodic parameter, only prosody differs with all segmental information intact. That is, native talkers' prosody is warped with Chinese talkers' prosody. The speech of English talkers' prosody and English talkers' segments (Epro-Eseg) is significantly different from that of Chinese talkers' prosody and English talkers' segments (Cpro-Eseg) in all parameters (see 
Table 1). This suggests that non-native Chinese talkers' prosody should serve as sufficient cue to differentiate native from non-native speech. However, when the synthesized speech of Cpro-Eseg is compared with that of Epro-Cseg (English talkers' prosody and Chinese talkers' segments), native listeners perceived a statistically stronger accent for the Epro-Cseg stimuli than the Eseg-Cpro stimuli (see Table 1). This implies that segmental cues seem to play a more salient role than prosody in the perception of foreign accent even though non-native talkers' prosody may, to some extent, make a contribution to foreign accent.

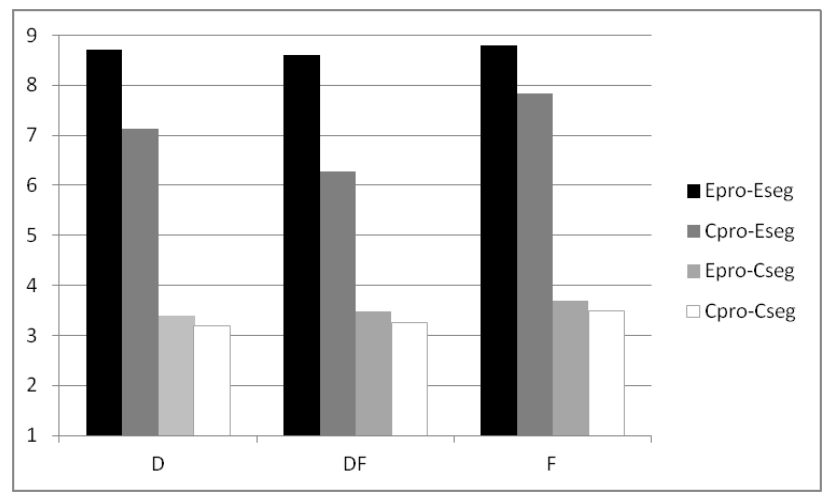

Figure 7. Foreign accent scores of the transplanted stimuli by the four transplanting methods: English talkers'

prosody-segment, Chinese talkers' prosody-English talkers' segment, English talkers' prosody-Chinese talkers' segment, and Chinese talkers' prosody-Chinese talkers' segment.

As presented in Table 1, the foreign accent scores of the Cpro-Cseg speech, though judged the highest/strongest, are not significantly different from those of the Epro-Cseg speech for all the prosodic parameters. That is, if Chinese L2 segments are combined with either English L1 prosody or Chinese L2 prosody, the synthesized stimuli of Cseg-Epro and Cseg-Cpro are not different enough to draw native listeners' detection of foreign accent. As shown in Figure 2, segments are a more prominent attribute to the perception of foreign accent than prosody. Similarly, the difference in natives' and non-natives' prosody may be perceptually masked by Chinese accented segments. Therefore, the foreign accent will be merely determined on the basis of segmental information, resulting in stronger foreign accent.

Let's turn to the question of which prosodic element, duration or pitch, is more influential to foreign accent in English. Figure 8 shows the roles of Chinese talkers' prosodic parameters (D, F, DF) when transplanted onto English talkers' segments.
According to a one-way ANOVA, the D and DF parameters are significantly different from $\mathrm{F}(\mathrm{F}=76.584$, D vs. $\mathrm{DF}$ : $\mathrm{p}=0.060$, DF vs. F: $p<0.05$, D vs. F: $p<0.05$ ). The foreign accent scores were better when English native talkers' pitch (F) was warped by that of Chinese talkers. Non-native Chinese talkers' duration was the main factor that made worse foreign accent in both $\mathrm{D}$ and DF synthesized speech. That is, native listeners of English detect non-native talkers' foreign accent, primarily relying on speech rate rather than intonation.

Table 1. Post hoc ANOVA of the four transplantation ways for the three prosodic parameters.

\begin{tabular}{|c|c|c|c|}
\hline \multicolumn{4}{|c|}{ D } \\
\hline & Cpro-Eseg & Epro-Cseg & Cpro-Cseg \\
\hline Epro-Eseg & $0.002^{*}$ & $0.012^{*}$ & $0.004^{*}$ \\
\hline Cpro-Eseg & & $0.001^{*}$ & $0.032^{*}$ \\
\hline Epro-Cseg & & & 0.439 \\
\hline \multicolumn{4}{|c|}{ DF } \\
\hline & Cpro-Eseg & Epro-Cseg & Cpro-Cseg \\
\hline Epro-Eseg & $0.000^{*}$ & $0.000^{*}$ & $0.000^{*}$ \\
\hline Cpro-Eseg & & $0.021^{*}$ & $0.026^{*}$ \\
\hline Epro-Cseg & & & 0.697 \\
\hline \multicolumn{4}{|c|}{$\mathbf{F}$} \\
\hline & Cpro-Eseg & Epro-Cseg & Cpro-Cseg \\
\hline Epro-Eseg & $0.000^{*}$ & $0.005^{\star}$ & $0.029 *$ \\
\hline Cpro-Eseg & & $0.018^{*}$ & $0.009^{*}$ \\
\hline Epro-Cseg & & & 0.285 \\
\hline
\end{tabular}

It should be noticed that foreign accent was worse when both duration and pitch were replaced together (DF) than when either pitch (F) or duration (D) was merely warped. Even though L2 pitch did not make a significant difference, it made the synthesized speech more accented when transplanted onto native segments in combination with L2 duration together. This is interpreted as stating that the other elements of prosody in native talkers' speech still remain to facilitate the synthesized stimuli to decrease foreign accent when only one was crossed.

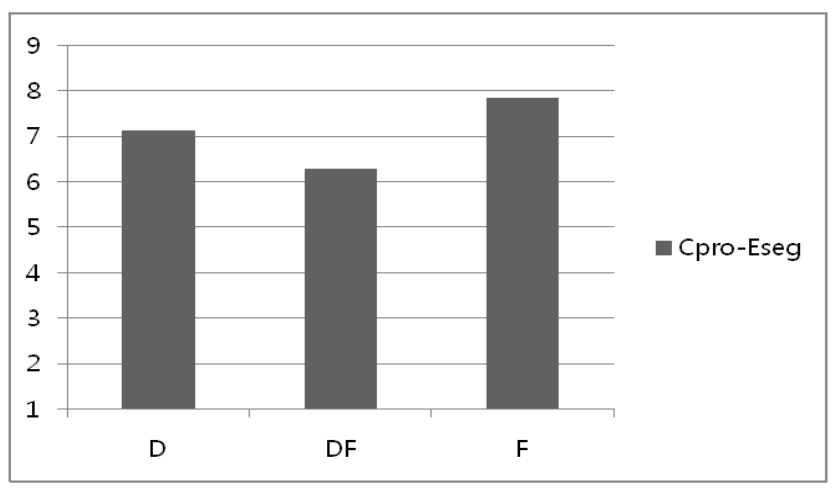

Figure 8. The transplanted sentences of Chinese talkers' prosody with English talkers' segments. 
Figure 9 presents the transplanted sentences of English talkers' prosody with Chinese talkers' segments. The overall scores are lower than those of Chinese prosody with English segments as in Figure 8, but they do not show a statistical difference $(\mathrm{F}=4.799, \mathrm{p}>0.05)$. That is, native listeners perceived a stronger foreign accent due to L2 segmental information regardless of which parameter of prosody was transplanted. This implies that in the presence of non-native talkers' segmental features, the prosodic effect may be smeared, which again illustrates segment is more obvious than prosody when perceiving foreign accent.

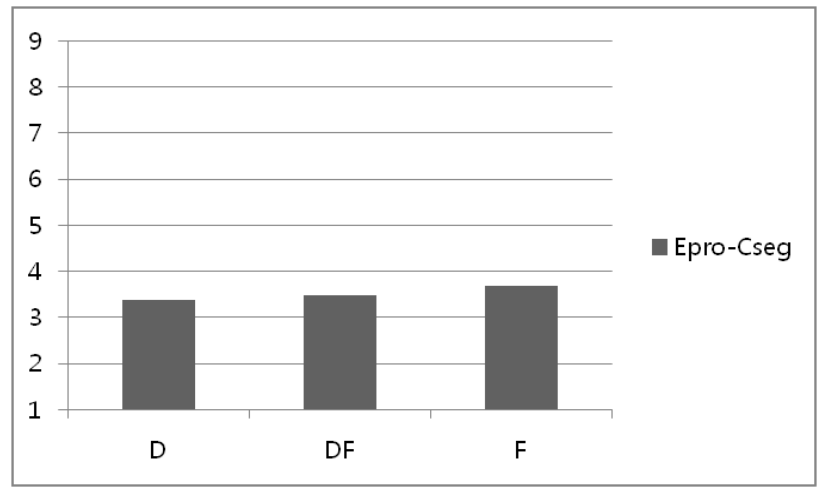

Figure 9. The transplanted sentences of English talkers' prosody with Chinese talkers' segments.

\subsubsection{Comprehensibility}

Let's turn to the comprehensibility results. Figure 10 shows the degree of easiness or difficulty the native listeners have felt toward the crossings between English talkers and Chinese high proficiency talkers. For each of the prosodic parameter, the comprehensibility scores are not significantly different between the stimuli of Chinese talkers' prosody with English talkers' segments (CHpro-Eseg) and those of English talkers' prosody with Chinese talkers' segments (Epro-CHseg, D: $\mathrm{t}=6.002$, $\mathrm{p}=0.575 ; \mathrm{DF}: \mathrm{t}=0.248, \mathrm{p}=0.225 ; \mathrm{F}: \mathrm{t}=8.132, \mathrm{p}=0.067$ ). Similarly, when native stimuli were synthesized with Chinese low proficiency stimuli, the CLpro-Eseg and the Epro-CLSeg speech did not show a statistical difference in comprehensibility as shown in <Figure $11>$ (D: $\mathrm{t}=5.809, \mathrm{p}=0.652 ; \mathrm{DF}: \mathrm{t}=3.822$, $\mathrm{p}=1.338 ; \mathrm{F}: \mathrm{t}=3.902, \mathrm{p}=0.887$ ). In contrast to the foreign accent results as shown in Figures 2 and 3, where non-native Chinese segments were more influential to foreign accent, native listeners detected almost the same degree of easiness/ difficulty in comprehending prosody-segment transplanted speech between native and non-native talkers, whether native segments with non-native prosody or vice versa.

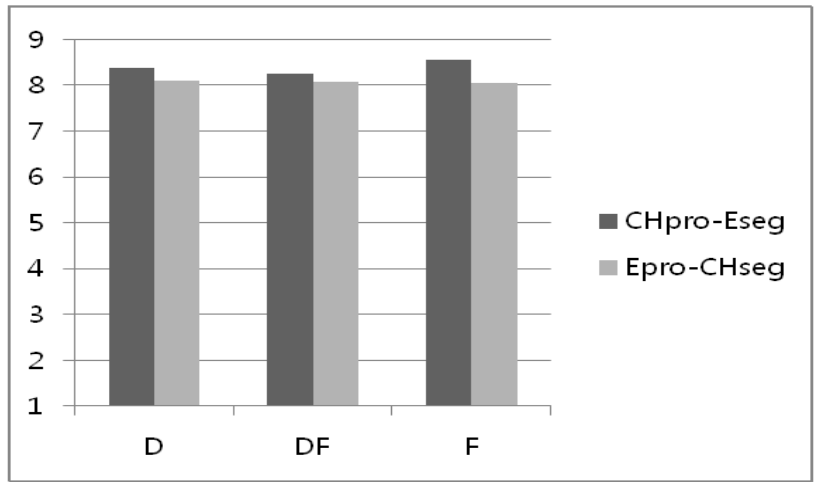

Figure 10. The comprehensibility scores of the combination of English talkers and Chinese high proficiency talkers.

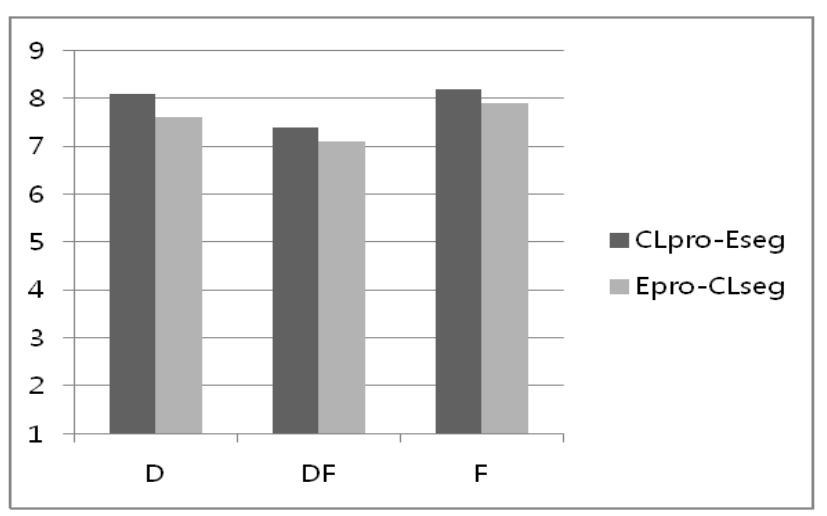

Figure 11. The comprehensibility scores of the combination of English talkers and Chinese low proficiency talkers.

The comprehensibility scores were compared for Chinese high and low proficiency talkers as shown in Figure 12 and Figure 13. Whether English talkers' prosody was overlaid onto Chinese talkers' segments or English talkers' segments were crossed with Chinese talkers' prosody, comprehensibility scores were all above 7 regardless of Chinese talkers' proficiency. According to the t-test, the synthesized speech did not show a significant difference between Chinese high and low proficiency talkers' segments as in Figure 11 (D: $t=9.001, \mathrm{p}=0.498$; DF: $\mathrm{t}=11.031, \mathrm{p}=0.058 ; \mathrm{F}: \mathrm{t}=7.217, \mathrm{p}=0.119)$ or between their prosody in Figure $12(\mathrm{D}: \mathrm{t}=7.936, \mathrm{p}=0.028 ; \mathrm{DF}: \mathrm{t}=10.337$, $\mathrm{p}=0.204 ; \mathrm{F}: \mathrm{t}=8.458, \mathrm{p}=0.092)$. That is, native listeners perceived the segments produced by Chinese low proficiency talkers as easy as that of Chinese high proficiency talkers when both of them were crossed with native talkers' prosody and vice versa. 


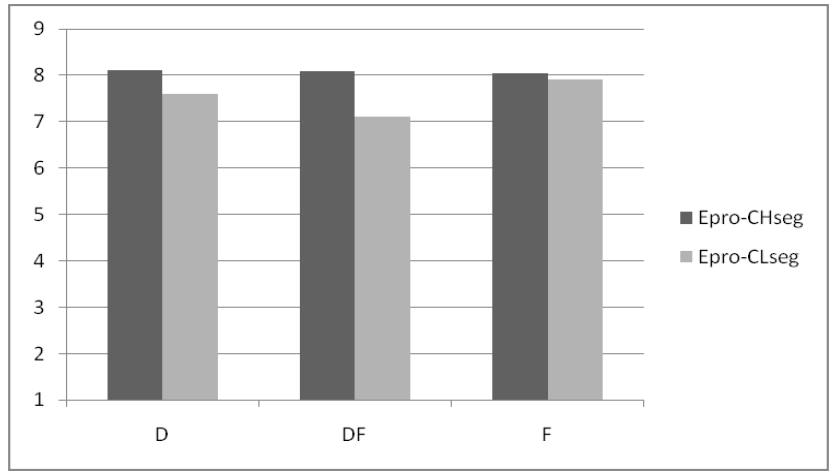

Figure 12. Comprehensibility scores for the Chinese high and low proficiency talkers when Chinese talkers' segments were crossed with English native talkers' prosody.

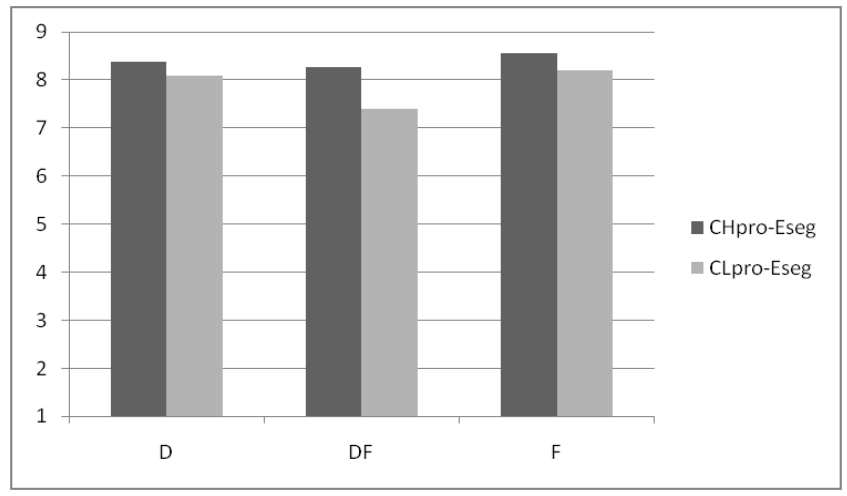

Figure 13. Comprehensibility scores for the Chinese high and low proficiency talkers when Chinese talkers' prosody was crossed with English native talkers' segments.

As discussed earlier in Figures 4 and 5, Chinese high and low proficiency talkers showed a significant difference in the foreign accent judgment when their segments were transplanted onto native talkers' prosody. However, there is no significant difference between high and low proficiency talkers in the comprehensibility of the transplanted speech as seen in Figures 12 and 13. This demonstrates that L2 talkers' proficiency does not seem to contribute to comprehensibility.

\subsubsection{Correlation}

The correlation of foreign accent and comprehensibility is still in debate; native listeners' comprehension is easier even for stronger accented L2 speech (Munro \& Derwing, 1995a) while stronger foreign accent has been generally assumed to render native listeners more difficulty in understanding L2 speech (Derwing \& Munro, 1997). The current study also examines how foreign accent is correlated with comprehensibility. As shown in Figure 14, there was no significant correlation between foreign accent scores and comprehensibility scores for Chinese high proficiency talkers $(r=0.0089, \mathrm{p}>0.01)$. Similarly, there was also no significant correlation between foreign accent and comprehensibility for Chinese low proficiency talkers as shown in Figure $15(\mathrm{r}=0.0462, \mathrm{p}>0.01)$. These results are consistent with Derwing and Munro (1997)'s study that non-native talkers' strong foreign accent does not always accompany difficulty in comprehensibility. Therefore, foreign accent scores may not be considered as a reliable predictor to judge comprehensibility.

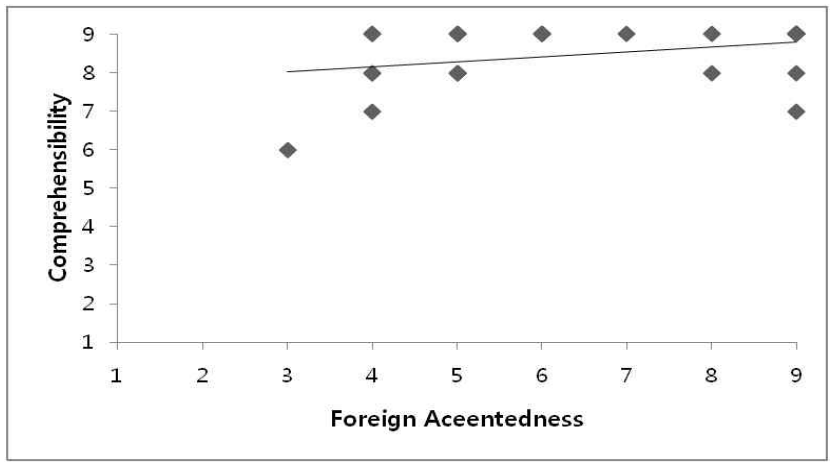

Figure 14. Pearson correlation of foreign accent and comprehensibility for Chinese high proficiency talkers.

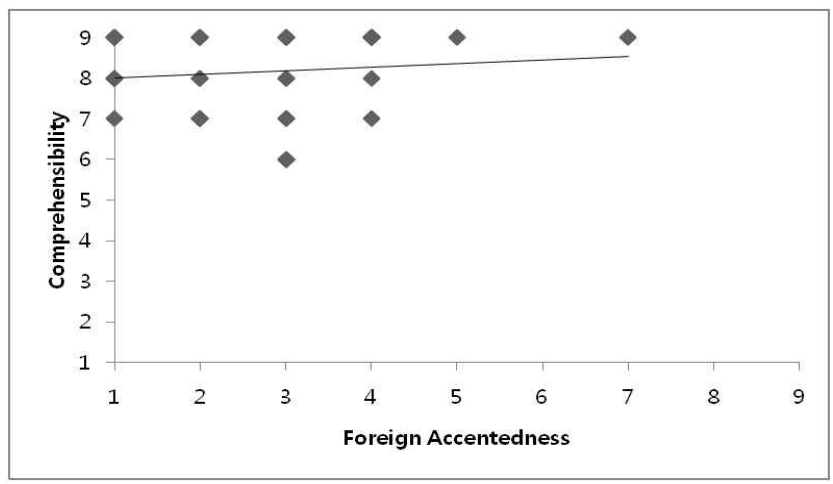

Figure 15. Pearson correlation of foreign accent and comprehensibility for Chinese low proficiency talkers.

\section{Acoustic analysis}

As discussed above, segmental information has a dominant effect on foreign accent over prosody, but prosodic contribution cannot be ignorable, though relatively smaller than segments. As the main concern of the present study is the contributions of prosody and its features to foreign accent and duration as opposed to pitch has been found to have a significant impact on the foreign accentedness of Chinese talkers as shown in Figure 8 , the temporal features of the Chinese speech are examined, focusing on speaking rate and pause duration, and pause frequency. The factors such as speaking rate, pause frequency 
and pause duration are all fluency-based, which are associated with non-native talkers' fluency (Trofimovich and Baker, 2007). These suprasegmentals describe the general current of speech and signify possible roots of difficulty for L2 learners, contributing to foreign accent (Mennen, 1998; Towell, 2002).

The speaking rate of L2 speech is commonly explored in previous work, especially in relation with foreign accent (Miller, Green \& Reeves, 1986; Anderson-Hsieh \& Koehler, 1988; Miller \& Volaitis, 1989; Munro \& Derwing, 1994; Munro \& Derwing, 1995b; Munron \& Derwing, 1998; Kessinger \& Blumstein, 1998; Trofimovich \& Baker, 2006). Munro \& Derwing (1998) showed that native listeners assessed the non-native speech produced at a slow speaking rate as more accented than that at a normal rate. They also found that non-native L2 learners often articulated L2 speech at a slower rate than did L1 talkers due to the difficulty in production of L2 speech. Anderson-Hsieh \& Koehler (1988) reported that speaking rate, either too slow or too fast, was perceived as an indicator of non-nativeness. Recently, Trofimovich and Baker (2006)'s study showed that speaking rate was a significant predictor of foreign accent.

Another aspect that reflects the degree of foreign accent is associated with pause frequency and duration. The existence of pause may express an L2 learner's difficulty of processing the target language (Schachter, Christenfeld, Ravina \& Bilous, 1991). Numerous studies on the pause duration and frequency of L2 speech reported that pause-related phenomena are a direct indicator of L2 talkers' proficiency (Goldman-Eisler, 1961; Lennon, 1990; Munro \& Derwing, 1994; Flege, Munro \& MacKay, 1995; Munro \& Derwing, 1998; Dankovicova, Gurd, Marshall, MacMahon, Stuart-Smith, Coleman \& Slater, 2001; Riazantseva, 2001). In Anderson-Hsieh and Venkatagiri (1994)'s study, they contended that non-native speakers with an intermediate level produced pauses more frequently and longer than the speakers with a high proficiency. Pickering (1999) similarly showed that the pauses in Chinese L2 speakers' production appeared to be longer and irregular than in that of native speakers. Kormos and Denes (2004)'s study showed that high proficient learners of L2 produced fewer pauses than low proficient L2 learners. Iwashita et al. (2008) also demonstrated that L2 learners with high proficiency level produced faster speech with less pauses.

In this section, we investigate which temporal factor among speaking rate, pause frequency and pause duration plays the most determinant role in foreign accent. The aim of the acoustic analysis is to determine how accurately and to what extent these suprasegmentals predict the degree of foreign accent.

All the recording stimuli from both Chinese high and low proficiency talkers were analyzed for speaking rate. Following Kang (2010), the number of syllables per second was calculated. That is, the total number of syllables articulated in a given sentence was divided by the total duration (including pause time). The measurements were submitted to a t-test for a statistical analysis to see if there is a difference in speaking rate between Chinese high and low proficiency talkers.

Figure 16 shows the mean values of speaking rate for Chinese high and low proficiency talkers. Chinese low proficiency talkers produced the speech stimuli with a slower rate than high proficiency talkers, and their difference is statistically significant $(\mathrm{t}=5.417, \mathrm{p}<0.05)$. This suggests that stronger accent of the low proficiency talkers is significantly attributed to slower speaking rate.

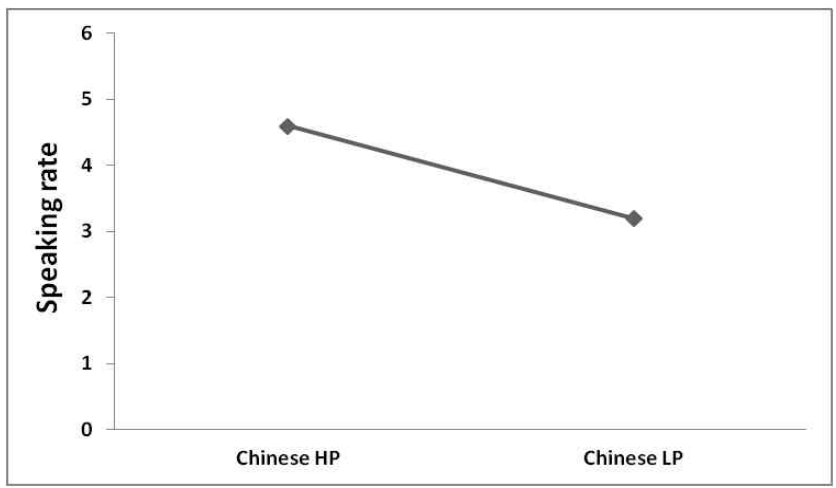

Figure 16. Averages of speaking rate for Chinese high and low proficiency talkers.

A pause is defined as any break in a speech longer than $0.1 \mathrm{~s}$ in length (Riazantseva, 2001). We measured pause frequency by dividing the total number of pauses by the total time (referred to second) in a given speech sample, following Kang (2010). Pause duration was calculated by dividing the total length of pauses by the total number of pauses (Kang, 2010).

Chinese high and low proficiency talkers' pause frequency and duration are exhibited in Figure 17 and Figure 18. The results show that Chinese low proficiency talkers produced more and longer pauses than high proficient talkers. The differences between the two groups are statistically different (pause frequency: $\mathrm{t}=17.088, \mathrm{p}<0.05$; pause duration: $\mathrm{t}=19.803, \mathrm{p}<0.05$ ). This indicates that both pause frequency and duration make a prominent contribution to foreign accent.

Chinese high proficient talkers' speech is faster and has less 
frequent and shorter pauses than that of low proficient talkers. Since all these temporal features are associated with talkers' proficiency, the results show that high proficient talkers are more fluent in L2 speech and that the duration factor, which was found to be dominant in the synthesized speech of Chinese prosody and native segments, might be attributed to these three temporal features. That is, the fluency-based prosodic features induced native listeners' judgment of "less accented" for high proficiency L2 speech.

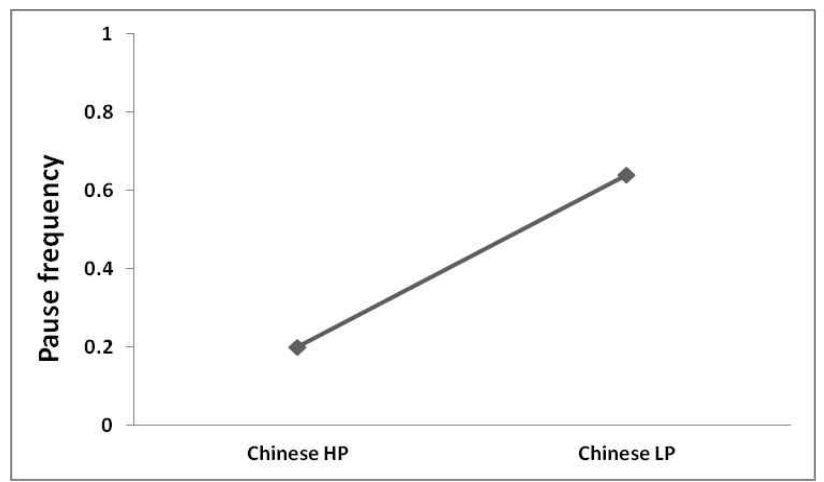

Figure 17. Averages of pause frequency for Chinese high and low proficiency talkers.

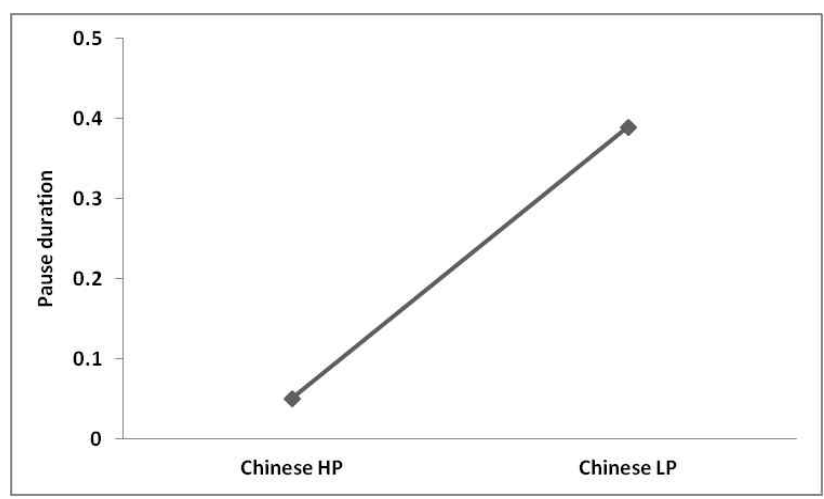

Figure 18. Averages of pause duration for Chinese high and low proficiency talkers.

According to Trofimovich and Baker (2007), a linear regression between the temporal features and foreign accent can tell us if the features are accurate predictors for the judgment of foreign accent. Linear regression is an approach that can manifest the relationship between a dependent variable $\mathrm{Y}$ and one or more explanatory variables $\mathrm{X}$ (Montgomery, Peck \& Vining, 2006). In the case of the current study, we can obtain the extent to which the dependent variable, that is, foreign accent, can be predicted by the explanatory variables which are the three temporal measurements. Usually, the variable values in the result of logistic regression analyses can illustrate how the explanatory variables $\mathrm{X}$ explain the dependent $\mathrm{Y}$. $\mathrm{B}$ value indicates correlation coefficient; it expresses the correlation between the explanatory variable and the dependent variable.

As shown in Table 2, the regression results $R^{2}$ indicate the explanation rates of the independent variables. That is, the prediction values of explanatory variables to the dependent variables. In the current study, $\mathrm{R}^{2}$ indicates how much the foreign accent is predicted by the three different temporal features (speaking rate, pause duration and pause frequency). SE $\mathrm{B}$ denotes the standard errors of the regression coefficient. Beta represents regression coefficient. It reveals the size of effect that the independent variables have on the dependent variable.

Table 2 presents that all of the three parameters, speaking rate, pause duration and pause frequency, can successfully predict foreign accent as their $\mathrm{R}^{2}$ values are all statistically significant. Speaking rate seems to predict foreign accent to a largest extent as its $\mathrm{R}^{2}$ is the highest. Pause duration is a stronger predictor than pause frequency. This is consistent with Trofimovich and Baker (2007)'s finding that non-native talkers' irregular speaking rate may first reveal their evident foreign accent of L2 speech.

Table 2. Regression analysis for acoustic measurements (speaking rate, pause frequency, and pause duration) as predictors of accentedness ratings.

\begin{tabular}{|c|ccccc|}
\hline & B & SE B & Beta & $\mathbf{R}^{2}$ & $\mathbf{t}$ \\
\hline $\begin{array}{c}\text { Speaking rate } \\
\text { Constant } \\
\text { Speaking rate }\end{array}$ & -8.22 & 1.21 & & & \\
\hline Pause duration & 3.06 & 0.05 & 0.74 & 0.81 & $\begin{array}{c}-6.81^{*} \\
3.96^{*}\end{array}$ \\
$\quad$ Constant & 6.33 & 0.36 & & & \\
Pause duration & -4.05 & 1.22 & -0.69 & 0.70 & $-3.47^{*}$ \\
\hline Pause frequency & & & & & $12.25^{*}$ \\
Constant & 5.64 & 0.27 & & & $14.06^{*}$ \\
Pause frequency & -2.39 & 0.81 & -0.53 & 0.58 & $-4.15^{*}$ \\
\hline
\end{tabular}

\section{Conclusion}

This study has investigated the contribution of prosody to the perception of foreign accent, observing the foreign accent judgments for the transplanted stimuli of native and non-native talkers' prosody and segments. Results indicated that segments play a relatively more important role than prosody in natives' perception of Chinese accented English speech. However, the contribution of prosody was also noticeable, though comparatively less than segments. Duration was found to be a 
determinant feature rather than pitch, and speaking rate and pause duration and frequency are the significant temporal attributes to the duration parameter in L2 speech.

In the evaluation of comprehensibility of the synthesized speech, prosody and segments do not seem to show a comparable weight in contrast to the foreign accent judgments. More interestingly, no correlation was found between foreign accent and comprehensibility. That is, the transplanted speech, if assessed as strong foreign accent, was rated as "relatively easily understood" in the comprehensibility judgment. This can be interpreted as stating that strong accent does not interfere with the comprehensibility for non-native speech.

\section{References}

Altenberg, E. P. (2005). The judgment, perception, and production of consonant clusters in a second language, Internationa Review of Applied Linguistics in Language Teaching. Vol. 43, 53-80.

Anderson-Hsieh, J. \& Koehler, K. (1988). The effect of foreign accent and speaking rate on native speaker comprehension, Language Learning. Vol. 38, No. 4, 561-613.

Anderson-Hsieh, J. \& Venkatagiri, H. (1994). Syllable duration and pausing in the speech of intermediate and high proficiency Chinese ESL speakers, TESOL Quarterly. Vol. $28,807-812$.

Avery, P. \& Ehrlich, S. (1992). Teaching American English pronunciation. Oxford: Oxford University Press.

Bent, T., Bradlow, A. R. \& Smith. (2008). Segmental errors in different word positions and their effects on intelligibility of non-native speech. In Edwards, J. G. \& Zampini, M. (Eds), Phonology and Second Language Acquisition, 332-347. Philadelphia: John Benjamins Publishing Company.

Brennan, E. M., Ryan, E. B. \& Dawson, W. E. (1975). Scaling of apparent accentedness by magnitude estimation and sensory modality matching, Journal of Psycholinguistic Research. Vol. 4, No.1, 27-36.

Boula de Mareuil, P. \& Vieru-Dimulescu, B. (2006). The Contribution of Prosody to the Perception of Foreign Accent, Phonetica. Vol. 63, 247-267.

Chao, Y. R. (1968). Language and symbolic systems. London: Cambridge University Press.

Coleman, E. B. (1962). Improving comprehensibility by shortening sentences, Journal of Applied Psychology. Vol 46, No. 2, 131-134
Dankovicova, J., Gurd, Marshall, J. M., MacMahon, J. C., Stuart-Smith, J., Coleman, J. S. \& Slater, A. (2001). Aspects of non-native pronunciation in a case of altered accent following stroke (foreign accent syndrome), Clinical Linguistics \& Phonetics. Vol. 15, No. 3, 195-218.

Derwing, T. M. \& Munro, M. J. (1997). Accent, intelligibility, and comprehensibility: evidence from four L1s, Studies in Second Language Acquisition. Vol. 19, 1-16.

Derwing, T. M., , M. J \& , R. I (2008). A longitudinal study of ESL learners fluency and comprehensibility development, Applied Linguistics. Vol. 29, No. 3, 359-380.

Flege, J. E. (1987). The instrumental study of L2 speech production: Some methodological considerations, Language Learning. Vol. 37, No. 2, 285-296.

Flege, J. E. (1993). Production and perception of a novel, second-language phonetic contrast, Journal of the Acoustic Society of America. Vol. 93, No. 3, 1589-1608.

Flege, J. E. (1995). Second language speech learning: Theory, findings and problems. In W. Strange (Ed.), Speech perception and linguistic experience: Issues in cross-language research, 233-277. Timonium: York Press.

Flege, J. E. (1988). Factors affecting degree of perceived foreign accent in English sentences, The Journal of the Acoustical Society of America. Vol. 84, No. 1, 70-79.

Flege, J. E. (1991). Age of learning affects the authenticity of voice-onset time (VOT) in stop consonants produced in a second language, Journal of the Acoustical Society of America. Vol. 89, No. 1, 395-411.

Flege, J. E., Frieda, E. M. \& Nozava, T. (1997). Amount of native-language (L1) affects the pronunciation of an $\mathrm{L} 2$, Journal of Phonetics. Vol. 25, 169-186.

Flege, J. E. \& Hillenbrand, J. (1984). Limits on phonetic accuracy in foreign language speech production, Journal of the Acoustic Society of America. Vol. 76, No. 3, 706-721.

Flege, J. E., Bohn, O. S. \& Jang, S. (1997). Effects of experience on non-native speaker's production and perception of English vowels, Journal of Phonetics. Vol. 25, 437-470.

Flege, J. E., Munro, M.J. \& MacKay, I. (1995). Factors affecting strength of perceived foreign accent in a second language, Journal of the Acoustic Society of America. Vol. 97, No. 5, 3125-3134.

Gass, S. \& Varonis, E. M. (1984). The effect of familiarity on the comprehensibility of nonnative speech, Language Learning. Vol. 34, No. 1, 65-87. 
Goldman-Eisler, F. (1961). The distribution of pause durations in speech, Language and Speech. Vol. 4, No. 4, 232-237.

Greene, J. \& Wells, E. (1927). The Cause and Cure of Speech Disorders: a Textbook for Students and Teachers on Stuttering, Stammering and Voice Conditions. New York: The Macmillan Company.

Iwashita, N., Brown, A., McNamara, T. \& O's Hagan, S. (2008). Assessed levels of second language speaking proficiency: how difficult? Applied Linguistics. Vol. 29, 24-49.

Kang, O. (2010). Relative salience of suprasegmental features on judgments of L2 comprehensibility and accentedness, System. Vol. 38, 301-315.

Kessinger, R. H. \& Blumstein, S. E. (1998). Effects of speaking rate on voice-onset time and vowel production: some implications for perception studies, Journal of Phonetics. Vol. 26, No. 2, 117-128.

Kormos, J. \& Denes, M. (2004). Exploring measures and perceptions of fluency in the speech of second language learners, System. Vol. 32, 145-164.

Koster, C. J. \& Koet, T. (1993). The Evaluation of Accent in the English of Dutchmen, Language Learning. Vol. 43, No. 1, 69-92.

Kuhl, P. K. (1991). Human adults and human infants show a 'perceptual magnet effect' for the prototypes of speech categories, monkeys do not, Perception \& Psychophysics. Vol. 50, 93-107.

Laeufer, C. (1992). Patterns of voicing-conditioned vowel duration in French and English, Journal of Phonetics. Vol. 20, 411-440.

Lee, J.-K. \& Liu, X. (2012). The relative weight of prosody and segment in the perception of Korean accented Chinese speech, Language and Linguistics. Vol. 54, 263-293.

Lennon, P. (1990). Investigating fluency in EFL: a quantitative approach, Language Learning. Vol. 40, No. 3, 387-417.

Levi, S. V., Winters, S. J. \& Pisoni, D. B. (2007). Speaker-independent factors affecting the perception of foreign accent in a second language, Journal of the Acoustical Society of America. Vol. 121, No. 4, 2327-2338.

Mack, M. (1989). Consonant and vowel perception and production: Early English-French bilinguals and English monolinguals, Perception \& Psychophysics. Vol. 46, No. 2, 187-200.

Magen, H. S. (1998). The perception of foreign-accented speech, Journal of Phonetics. Vol. 26, 381-400.
Major, R. C., Fitzmaurice, S. F., Bunta, F. \& Balasubramanian, C. (2002). The effects of nonnative accents on listening comprehension: implications for ESL assessment, TESOL Quarterly. Vol. 36, No. 2, 173-190.

Matsuura, H., Chiba, R. \& Fujieda, M. (1999). Intelligibility and comprehensibility of American and Irish Englishes in Japan, World Englishes. Vol. 18, No. 1, 49-62.

Mennen, I. (1998). Second language acquisition of intonation: The case of peak alignment, Chicago Linguistica Symposium. Vol. 34, 327-362.

Mildner, V. \& Horga, D. (1999). Relations between second language proficiency and formant defined vowel space. In the Proceedings of the XIVth International Congress of Phonetic Sciences (ICPhS 99), 1455-1458.

Miller, J. L., Green, K.P. \& Reeves, A. (1986). Speaking rate and segments: a look at the relation between speech production and speech perception for the voicing contrast, Phonetica. Vol. 43, 106-115.

Miller, J. L. \& Volaitis, L. E. (1989). Effect of speaking rate on the perceptual structure of a phonetic category. Attention, Perception, \& Psychophysics. Vol. 46, No, 6, 505-512.

Missaglia, F. (1999). Contrastive prosody in SLA-an empirical study with adult Italian learners of German, In the Proceedings of 14th International Congress of Phonetic Sciences, 551-554.

Morley, J. (1991). The pronunciation component of teaching English to speakers of other languages, TESOL Quarterly. Vol.25, 481-520.

Munro, M. J. (1995). Non-segmental Factors in Foreign Accent: Ratings of filtered Speech, Studies in Second Language Acquisition. Vol. 17, 17-34.

Munro, M. J. (2008). Foreign accent and speech intelligibility. In Edwards, J. G. \& Zampini, M. (Eds.), Phonology and Second Language Acquisition, 193-218. Philadelphia: John Benjamins Publishing Company.

Munro, M. J. \& Derwing, T. M. (1994). Evaluations of foreign accent in extemporaneous and read material, Language Testing. Vol. 11, No. 3, 253-266.

Munro, M. J. \& Derwing, T. M. (1995a). Foreign Accent, Comprehensibility, and Intelligibility in the Speech of Second Language Learners, Language Learning. Vol. 49, 285-310.

Munro, M. J. \& Derwing, T. M. (1995b). Processing time, accent, and comprehensibility in the perception of native and foreign-accented speech, Language and Speech. Vol. 38, No. 3, 289-306. 
Munro, M. J. \& Derwing, T. M. (1998). The effect of speaking rate on listener evaluations of native and foreign accented speech, Language Leaning. Vol. 48, 159-182.

Munro, M. J. \& Derwing, T. M. (2001). Modeling perceptions of the accentedness and comprehensibility of L2 speech: the role of speaking rate, Studies in Second Language Acquisition. Vol. 23, 451-468.

Pallier, C., Bosch, L. \& Sebastian Galles, N. (1997). A limit on behavioral plasticity in speech perception, Cognition. Vol. 64, No. 3, 9-17.

Pennington, M., Ellis, N. (2000). Cantonese speakers' memory for English sentences with prosodic cues, The Modern Language Journal. Vol. 84, 372-389.

Pickering, L. (1999). An Analysis of Prosodic Systems in the Classroom Discourse of Native Speaker and Nonnative Speaker Teaching Assistants. Unpublished Doctoral Dissertation. University of Florida.

Piske, T., MacKay, I. R. A. \& Flege, J. E. (2001). Factors affecting degree of foreign accent in an L2: A review, Journal of Phonetics. Vol. 29, 191-215.

Riazantseva, A. (2001). Second language proficiency and pausing: A study of Russian speakers of English, Studies in Second Language and Acquisition. Vol. 23, 497-526.

Riney, T. J., Takada, M. \& Ota, M. (2000). Segmentals and global foreign accent: the Japanese flap in EFL, TESOL Quarterly. Vol. 34, No. 4, 711-737.

Schachter, S., Christenfeld, N., Ravina, B. \& Bilous, F. (1991). Speech disfluency and the structure of knowledge, Journal of Personality and Social Psychology. Vol. 60, 362-367.

Schmid, P. M. \& Yeni-Komshian, G. H. (1999). The effects of speaker accent and target predictability on perception of mispronunciations, Journal of Speech, Language, and Hearing Research. Vol.42, 56-64.

Tekman, H. G. (1997). Interactions of perceived intensity, duration, and pitch in pure tone sequences, Music Perception. Vol. 14, No. 3, 281-294.

Towell, R. (2002). Relative degrees of fluency: A comparative case study of advanced learners of French, International Review of Applied Linguistics. Vol. 40, 117-150.

Trofimovich, P. \& Baker, W. (2007). Learning prosody and fluency characteristics of second language speech: the effect of experience on child learners' acquisition of five suprasegmentals, Applied Psycholinguistics. Vol. 28, 251-276.

Tsukada, K. (2005). Cross-language speech perception of final stops by Australian-English, Japanese and Thai Listeners, In the Proceedings of the ISCA Workshop on Plasticity in Speech Perception, 244-247.

Tsukada, K., Birdsong, D., Mack, M., Sung, H., Bialystok, E. \& Flege, J. E. (2004). Release bursts in English word-final voiceless stops produced by native English and Korean adults and children, Phonetica. Vol. 61, 67-83.

Van els, T. \& De Bot, K. (1987). The Role of Intonation in Foreign accent, Modern Language Journal. Vol. 71, 147-155.

Varonis, E. M. \& Gass, S. (1982). The comprehensibility of non-native speech, Studies in Second Language Acquisition. Vol. 4, 114-136.

Walley, A. C. \& Flege, J. E. (1998). Effect of lexical status on children's and adults' perception of native and non-native vowels, Journal of Phonetics. Vol. 27, 307-332.

Wayland, R. (1997). Non-native production of Thai: acoustic measurements and accentedness ratings, Applied Linguistics. Vol. 18, 345-373.

Wode, H. (1980). Phonology in L2 acquisition. In S. W. Felix (Ed.), Second Language Development: Trends and Issues, 123-136.

Yoon. K.-C. (2006). Imposing native speaker's prosody onto non-native speaker's utterance. Paper presented at WESPAC IX.

\section{- Liu, Xing}

Department of English Language and Literature University of Seoul 90 Jeonnong-dong, Dongdaemun-gu, Seoul, 130-743, Korean Email: fayemeteor@naver.com

\section{- Lee, Joo-kyeong, Corresponding author} Department of English Language and Literature University of Seoul 90 Jeonnong-dong, Dongdaemun-gu, Seoul, 130-743, Korean Email: jookyeong@uos.ac.kr 


\section{Appendices}

1. Reading passage for the Accentedness Task

Nowadays, Koreans often travel abroad for sightseeing, school, and work. Since Koreans do not need a visa to visit the United States anymore, many go there. When you visit another country, you should follow that country's customs. One American custom is tipping. In the U.S., people often receive tips for providing services. In Korea, tipping is rare. However, in many Western countries, tipping is important. So you should know about it.

2. Recording stimuli for the main experiment
(1) Go to sleep!
(2) Where does Mary live?
(3) I'm going to the shopping mall.
(4) Can you turn off your phone?
(5) The man bought a computer. 